\title{
Banking firm and hedging over the business cycle
}

\author{
Udo Broll · Kit Pong Wong
}

Received: 22 October 2008 / Accepted: 14 January 2010 / Published online: 26 January 2010

(C) Springer-Verlag 2010

\begin{abstract}
This paper examines the behavior of a banking firm under risk. The banking firm can hedge its risk exposure by trading futures contracts. The banking firm is risk averse and possesses a utility function defined over its end-of-period income and a state variable that denotes the business cycle of the economy. We show that the banking firm optimally opts for an overhedge or an under-hedge, depending on whether the returns on the futures contracts are negatively or positively correlated with the business cycle of the economy, respectively. Thus, the business cycle of the economy is an important determinant in shaping the banking firm's optimal hedging strategy.
\end{abstract}

Keywords Banks • Return risk • Hedging • Business cycle • State-dependent utility

JEL Classification $\mathrm{G} 13 \cdot \mathrm{G} 21$

\section{Introduction}

Continually changing volatilities on financial markets coupled with rises in interest rate, output prices, and foreign exchange rates have led to the develop-

\footnotetext{
U. Broll ( $\varangle)$

Department of Management and Economics, Technische Universität Dresden, Helmholtzstr. 10, 01062 Dresden, Germany

e-mail: udo.broll@tu-dresden.de

K. P. Wong

School of Economics and Finance, University of Hong Kong,

Pokfulam Road, Hong Kong, China

e-mail: kpwong@econ.hku.hk
} 
ment of various futures markets. These risk-sharing markets have experienced a remarkable rate of growth throughout the world and resulted in the creation of many new hedging instruments. Such hedging instruments allow a better control of risk exposure faced by national and international banking firms (see, for example, Freixas and Rochet 2008; Bessis 2009).

In an important contribution to the literature on futures markets, Benninga et al. (1983) addressed the issue of optimal hedging in the presence of unbiased futures prices. They derived conditions for the optimal hedge to be a fixed proportion of the cash position, regardless of the agent's utility function. This result is important because of the sizeable research on theoretical and empirical hedging that abstracts from the particular utility functions of riskaverse, expected utility maximizers (see, for example, Dewatripont and Tirole 1994; Wong 1997; Battermann et al. 2000; Broll et al. 2001; Broll and Wong 2002; Broll and Eckwert 2006; Freixas and Rochet 2008).

The novelty of this note is to incorporate the business cycle of an economy into the utility function of a banking firm. To hedge its risk exposure, the banking firm trades futures contracts. We show that the banking firm optimally opts for an over-hedge or an under-hedge, depending on whether the returns on the futures contracts are negatively or positively correlated with the business cycle of the economy, respectively. This implies that the banking firm takes the business cycle of the economy into consideration when devising its optimal hedging strategy (for an overview on contemporary macroeconomics and the business cylce see Dixon 2007).

The banking firm is risk averse and possesses a utility function defined over its end-of-period income and a state variable that denotes the business cycle of the economy. We assume that the banking firm's preferences are state dependent for a few reasons (Karni et al. 1983; Karni 1985). As argued in the literature the state-dependent approach can be regarded as a reduced form for a more complex expected utility model in which there is exogenous variation in wealth and relative prices (see Briys and Schlesinger 1993; Broll and Wong 2002). Furthermore, state-dependent preferences can be defined as the case where there are exogenous fluctuations in wealth (see Briys et al. 1993), or as the case where there is uncertainty about the general price level, but wealth is expressed in nominal terms (see Adam-Müller 2000).

The plan of the paper is as follows. Section 2 develops the model of a competitive banking firm under uncertainty. It is assumed that the banking firm's preferences are state dependent for some economic reasons. Section 3 derives and discusses the main results of the model. Section 4 offers some concluding remarks.

\section{The model}

We develop a simple model of a banking firm that makes its financial and hedging decisions in a one-period horizon. To begin, the banking firm is endowed with fixed equity capital, $K$, and has to issue deposits, $D$, to finance the 
acquisition of financial assets, $A$. Deposits are fully insured so that depositors demand a known one-plus deposit rate, $r_{D}$, which is much lower than the cost of equity capital faced by the banking firm. The banking firm as such would like to issue as many deposits as possible, albeit subject to a capital adequacy requirement that prohibits the capital-to-deposits ratio from falling below a given threshold, $\kappa>0$. Under the binding capital adequacy requirement, the maximum amount of deposits issued by the banking firm is thus $D=\kappa K$.

The financial assets acquired by the banking firm generate a random gross return, $\tilde{r}_{A}$, at the end of the period. To hedge its risk exposure, the banking firm sells (purchases if positive) $H$ units of futures contracts at the prespecified gross return, $r_{F}$. The actual gross return, $\tilde{r}$, of the futures contracts to be realized at the end of the period is correlated with $\tilde{r}_{A}$. The banking firm's random end-of-period income, $\tilde{\Pi}$, is given by

$$
\tilde{\Pi}=\tilde{r}_{A} A-r_{D} D+\left(r_{F}-\tilde{r}\right) H,
$$

where $D=\kappa K$ and

$$
A=K+D=(1+\kappa) K .
$$

The banking firm is risk averse and possesses a utility function, $U(\Pi, s)$, defined over its end-of-period income, $\Pi$, and a state variable, $s$, that denotes the business cycle of the economy. We assume that the banking firm's preferences are state dependent for a few reasons. ${ }^{1}$ As argued by Briys and Schlesinger (1993) and Broll and Wong (2002), the state-dependent approach can be regarded as a reduced form for a more complex expected utility model wherein there is exogenous variation in wealth and relative prices. Alternatively, the state-dependent approach can be defined as the case where there are exogenous fluctuations in base wealth (see Briys et al. 1993), or as the case where there is uncertainty about the general price level, but wealth is expressed in nominal terms (see Adam-Müller 2000). By assumption the utility function, $U(\Pi, s)$, satisfies that $U_{\Pi}(\Pi, s)>0, U_{\Pi \Pi}(\Pi, s)<0$, and $U_{\Pi s}(\Pi, s)>$ 0 , where subscripts denote partial derivatives.

The ex-ante decision problem of the banking firm is given by

$$
\max _{H} E[U(\tilde{\Pi}, \tilde{s})],
$$

where $E(\cdot)$ is the expectation operator and $\tilde{\Pi}$ is defined in Eq. 1 . The necessary and sufficient condition for the unique solution to program (2) is given by

$$
E\left[U_{\Pi}\left(\tilde{\Pi}^{*}, \tilde{s}\right)\left(r_{F}-\tilde{r}\right)\right]=0,
$$

where an asterisk $\left(^{*}\right)$ indicates an optimal level.

\footnotetext{
${ }^{1}$ See Karni et al. (1983) for an axiomatization of expected utility maximizing behavior with subjective probabilities and state-dependent preferences. See also Karni (1985) for a comprehensive introduction of the theory of state-dependent preferences.
} 


\section{Optimal hedging policy of the bank}

In the empirical banking and hedging literature, the usual assumption about $\tilde{r}_{A}$ and $\tilde{r}$ would be that

$$
\tilde{r}_{A}=\alpha+\beta \tilde{r}+\tilde{\varepsilon}
$$

where $\alpha$ and $\beta$ are constants, and $\tilde{\varepsilon}$ is a zero-mean random variable independent of $\tilde{r}$. This is referred to as the regression dependence between $\tilde{r}_{A}$ and $\tilde{r}$. Under this assumption, if the futures contracts are unbiased, i.e., $r_{F}=E(\tilde{r})$, and the utility function is state independent, then it is well-known that the optimal hedge policy is always a beta-hedge in that $H^{*}=\beta A$, irrespective of the underlying preferences and the joint probability distributions of $\tilde{r}_{A}$ and $\tilde{r}$.

We show in the following proposition that such a beta-hedge is no longer optimal should the banking firm's utility function depend on the business cycle of the economy.

Proposition 1 Assume that the futures contracts are unbiased and that the regression dependence between $\tilde{r}_{A}$ and $\tilde{r}$ holds. (a) The banking firm overhedges its risk exposure, i.e., $H^{*}>\beta A$, if the return risk is negatively correlated with the business cycle. (b) The banking firm underhedges its risk exposure, i.e., $H^{*}<\beta A$, if the return risk is positively correlated with the business cycle.

Proof Using the covariance operator, $\operatorname{cov}(\cdot, \cdot)$, we recast Eq. 3 as

$$
E\left[U_{\Pi}\left(\tilde{\Pi}^{*}, \tilde{s}\right)\right]\left[r_{F}-E(\tilde{r})\right]-\operatorname{cov}\left[U_{\Pi}\left(\tilde{\Pi}^{*}, \tilde{s}\right), \tilde{r}\right]=0 .
$$

Since $r_{F}=E(\tilde{r})$, Eq. 4 reduces to

$$
\operatorname{cov}\left[U_{\Pi}\left(\tilde{\Pi}^{*}, \tilde{s}\right), \tilde{r}\right]=0 .
$$

Using Eq. 1 and the regression dependence between $\tilde{r}_{A}$ and $\tilde{r}$, we can write Eq. 5 as

$$
\operatorname{cov}\left\{U_{\Pi}\left[\tilde{r}\left(\beta A-H^{*}\right)+(\alpha+\tilde{\varepsilon}) A-r_{D} D+r_{F} H^{*}, \tilde{s}\right], \tilde{r}\right\}=0 .
$$

Consider first the case that $\operatorname{cov}(\tilde{r}, \tilde{s})<0$. Suppose that $H^{*} \leq \beta A$. Since $U_{\Pi \Pi}(\Pi, s)<0$ and $U_{\Pi s}(\Pi, s)>0$, the covariance term on the left-hand side of Eq. 6 would be positive, a contradiction. Hence, it must be true that $H^{*}>\beta A$ when $\operatorname{cov}(\tilde{r}, \tilde{s})<0$.

Now, consider the case that $\operatorname{cov}(\tilde{r}, \tilde{s})>0$. Suppose that $H^{*} \geq \beta A$. Since $U_{\Pi \Pi}(\Pi, s)<0$ and $U_{\Pi s}(\Pi, s)>0$, the covariance term on the left-hand side of Eq. 6 would be negative, a contradiction. Hence, it must be true that $H^{*}<\beta A$ when $\operatorname{cov}(\tilde{r}, \tilde{s})>0$.

The intuition of this proposition is as follows. As long as $\operatorname{cov}(\tilde{r}, \tilde{s}) \neq 0$, the futures contracts are useful hedging instruments not only for the financial assets but also for the business cycle of the economy. When $\operatorname{cov}(\tilde{r}, \tilde{s})<(>) 0$, it follows from $U_{\Pi s}(\Pi, s)>0$ that it is optimal to buy (sell) the futures contracts. This additional hedging need arising from the business cycle of the economy 
makes the banking firm deviate from a beta-hedge in general, and opt for an over-hedge (under-hedge) in particular.

\section{Concluding remarks}

In this paper, we have examined the behavior of a banking firm whose utility function varies with the business cycle of an economy. As argued in the literature the state-dependent approach can be regarded as a reduced form for a more complex expected utility model wherein there is exogenous variation in wealth. To hedge its risk exposure, the banking firm trades futures contracts. Within this framework, we have shown that it is optimal for the banking firm to opt for an over-hedge or an under-hedge, depending on whether the returns on the futures contracts are negatively or positively correlated with the business cycle of the economy, respectively. This implies that the banking firm takes the business cycle of the economy into consideration when devising its optimal hedging strategy.

Acknowledgement We would like to thank Francesco Franco, the co-editor of this journal, for helpful comments and suggestions.

\section{References}

Adam-Müller AFA (2000) Hedging price risk when real wealth matters. J Int Financ Money 19(4):549-560

Battermann HL, Braulke M, Broll U, Schimmelpfennig J (2000) The preferred hedge instrument. Econ Lett 66(1):85-91

Benninga S, Eldor R, Zilcha I (1983) Optimal hedging in the futures market under price uncertainty. Econ Lett 13(2-3):141-145

Bessis J (2009) Risk management in banking, 3rd edn. Wiley, Chichester

Briys E, Schlesinger H (1993) Optimal hedging when preferences are state dependent. J Futures Mark 13(5):441-451

Briys E, Crouhy M, Schlesinger H (1993) Optimal hedging in a futures market with background noise and basis risk. Eur Econ Rev 37(5):949-960

Broll U, Eckwert B (2006) Transparency in the interbank market and the volume of bank intermediated loans. Int J Econ Theory 2(2):123-133

Broll U, Wong KP (2002) Optimal full-hedging under state-dependent preferences. Q Rev Econ Finance 42(5):937-943

Broll U, Chow KW, Wong KP (2001) Hedging and nonlinear risk exposure. Oxf Econ Pap 53(2):281-296

Dewatripont M, Tirole J (1994) The prudential regulation of banks. MIT, Cambridge

Dixon HD (2007) Imperfect competition and contemporary macroeconomics. Port Econ J 6(2): $89-93$

Freixas X, Rochet JC (2008) Microeconomics of banking, 2nd edn. MIT, Cambridge

Karni E (1985) Decision making under uncertainty: the case of state-dependent preferences. Harvard University Press, Cambridge

Karni E, Schmeidler D, Vind K (1983) On state dependent preferences and subjective probabilities. Econometrica 51(4):1021-1031

Wong KP (1997) On the determinants of bank interest margins under credit and interest rate risk. J Bank Financ 21(2):251-271 